\title{
Perancangan Sistem Penjualan Online Berbasis Web Untuk Petani Tanaman Bunga Di Desa Cihideung
}

\author{
Jordan Nababan dan Henry Pandia \\ Fakultas Teknologi Informasi, Universitas Advent Indonesia
}

\begin{abstract}
Abstrak
Salah satu kendala petani tanaman bunga adalah bagaimana memasarkan produk tanaman yang dihasilkan, dan hal tersebut yang menjadi landasan penelitian mengenai perancangan sistem penjualan berbasis web untuk petani tanaman bunga di desa Cihideung. Adapun alasan dirancangnya sistem penjualan online adalah karena para petani di desa Cihideung belum menggunakan sistem yang dapat membantu dalam proses penjualan. Tujuan perancangan sistem penjualan online adalah untuk dapat membantu petani tanaman bunga dalam mengelola data penjualan agar lebih efektif. Perancangan sistem penjualan ini menerapkan model air terjun (waterfall model), yang melakukan pendekatan proses perancangan secara sistematis, yang dimulai pada tingkat analisa sistem, desain, kode, dan pengujian. Hasil dari perancangan sistem tersebut menjadikan suatu sistem penjualan online yang dapat membantu petani tanaman bunga dalam menjual hasil dan meningkatkan fleksibilitas bagi customeryang ingin berbelanja tanpa harus datang ke tempat. Namun sistem tersebut masih memiliki kekurangan, yaitu tidak memliki sistem keamanan untuk transaksi pembayaran online, karena sistem pembayaran yang dilakukan hanya dengan melalui transfer rekening antar bank pembeli dan penjual. Oleh sebab itu, disarankan agar ada penelitian berikutnya yang dapat meningkatkan fungsi sistem keamanan untuk sistem pembayaran transaksi online, sehingga dapat memudahkan bagi pengunjung web yang berada di luar negeri yang ingin bertransaksi atau membeli tanaman bunga.
\end{abstract}

Kata-kata Kunci: Sistem Penjualan Bunga, Berbasis Web

\section{Design of Web Based Online Selling System for Flower Farmers at Cihideung Village}

One obstacle for flower farmers is how to market the crop products that are produced, and this is the basis of research on designing a web-based sales system for flower plant farmers in Cihideung village. The reason for designing the online sales system is because farmers in the village of Cihideung have not used a system that can assist in the sales process. The purpose of designing an online sales system is to be able to help flower plant farmers in managing sales data to be more effective. The design of this sales system applies the waterfall model, which approaches the design process systematically, which starts at the level of system analysis, design, code, and testing. The results of the system design make it an online sales system that can help flower plant farmers sell their products and increase flexibility for customers who want to shop without having to come to the place. However, the system still has disadvantages, namely not having a security system for online payment transactions, because the payment system is carried out only through transferring bank accounts to buyers and sellers. Therefore, it is recommended that there be further research that can improve the function of the security system for online transaction payment systems, so that it can make it easier for web visitors abroad who want to transact or buy flower plants.

\section{Pendahuluan}

Seiring berkembangnya teknologi informasi, industri-industri lain yang bergerak di semua bidang telah memanfaatkan fasilitas-fasilitas dari teknologi informasi, seperti mencari informasi, membuat media aplikasi sampai berjualan secara online. Dari semua fasilitas yang ada, mayoritas digunakan oleh masyarakat adalah fasilitas berjualan secara online atau biasa disebut dengan $e$ commerce, salah satu aspek yang paling mendukung adalah adanya fasilitas e-commerce yang dapat membantu dalam proses penjualan atau penawaran produk.

Menurut buku e-commerce untuk Indonesia lebih baik, bisnis model e-commerce menawarkan berbagai keunggulan misalnya lebih cepat, lebih hemat, lebih praktis dan berbagai keunggulan lain. 
Dari mana saja dan kapan saja proses jual beli barang dan jasa bisa dilakukan, menguntungkan berbagai pihak yang terkait.

Pembeli dan penjual tidak harus bertatap muka, buka 24 jam, bisa menjangkau wilayah yang sangat luas bahkan melewati batas-batas negara. Proses bisnis bisa dilakukan dari rumah dengan berbagai media seperti handphone, komputer atau lainnya.

Menurut para petani tanaman di desa Cihideung saat ini penjualan tanaman bunga dilakukan dengan cara manual, penjualan tanaman bunga di desa Cihideung pada umumnya bergantung kepada pengunjung yang sedang berwisata ke daerah agrowisata desa Cihideung pada akhir pekan, karena itu para petani bunga dan tanaman di desa Cihideung kesulitan dalam menjual tanaman bunga mereka kepada konsumen.

\section{Landasan Teori Sistem}

SIM adalah kependekan dari sistem informasi manajemen yang merupakan salah satu jenis dari sistem informasi. Untuk dapat mengerti pengertian SIM, lebih baik terlebih dahulu memahami definisi sistem informasi (SI). Menurut Soeherman dan Pinontoan (2008:35), sistem informasi adalah serangkaian komponen berupa manusia, prosedur, data dan teknologi (seperti komputer) yang digunakan untuk melakukan sebuah proses untuk menghasilkan informasi yang bernilai untuk pengambilan keputusan. Adapun menurut Ladjamudin (2005:13)

\section{Web}

Menurut betha sidik, dan husni iskandar pohan (2014:1), ruang informasi dalam internet, dengan menggunakan

MySQL adalah salah satu jenis database server yang sering digunakan dalam perancangan program. Mysql menggunakan SQL sebagai bahasa dasar untuk mengakses databasenya dan juga bersifat open source.

\section{Analisa dan Perancangan \\ Analisa kebutuhan sistem}

Berdasarkan hasil wawancara dengan pihak petani, prosedur yang sedang berjalan di desa Cihideung saat ini masih menggunakan sistem penjualan yang konvensional, yaitu petani menjual tanaman mereka di depan rumah mereka, atau mereka mengirim tanaman bunga mereka ke toko bunga yang ada di kota Bandung untuk di jual-belikan di toko tersebut. Para petani mempunyai beberapa masalah dalam proses penjualan yang mereka alami selama ini, menurut mereka masalah tersebut dapat mengurangi pendapatan mereka, mereka sangat kesulitan untuk mengatasi masalah tersebut, begitu juga dengan para konsumen yang ingin mencari bunga yang sesuai dengan keinginan dan kebutuhan yang tepat. Selama ini konsumen hanya dapat membeli tanaman bunga para petani di desa Cihideung ketika para konsumen sedang berada di desa tersebut:

\section{Tampilan Halaman Login}

Tampilan halaman home ditampilkan ketika pengguna membuka website kampungbunga.com, pada halaman ini userakan melihat halaman utama yang terdapat menu untuk registrasi dan juga login kedalam website kampungbunga.com. Tampilan halaman home dapat dilihat pada Gambar 1. 


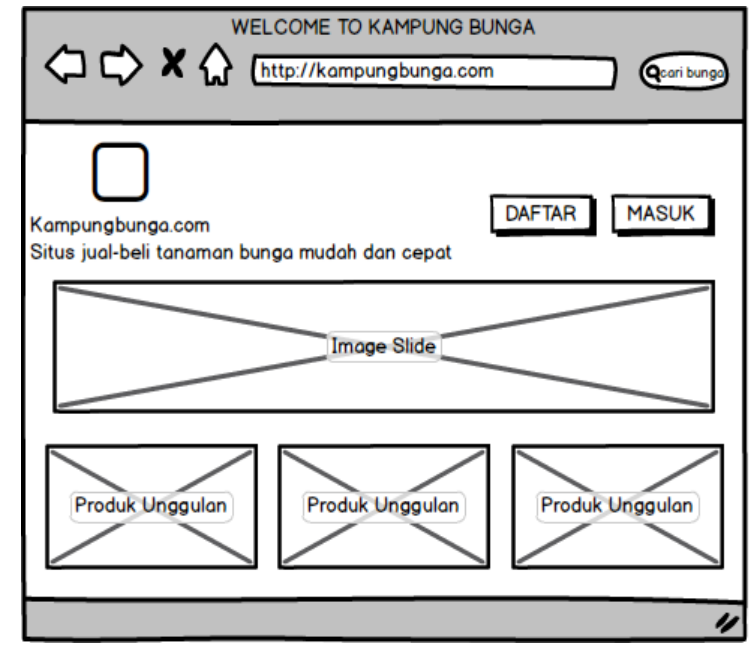

Gambar 1 Rancangan Halaman Login

\section{Tampilan Registrasi}

Tampilan halaman registrasi ditampilkan ketika usermenekan tombol registrasi, pada halaman ini user akan mengisi semua form yang disediakan. Seperti form username, password, alamat, nomor $\mathrm{HP}$, dan email. Lalu user harus menyetujui syarat dan ketentuan untuk mendaftar dengan meng klik tanda di atas tombol daftar, dan baru tekan tombol daftar untuk menyelesaikan proses pendaftaran.

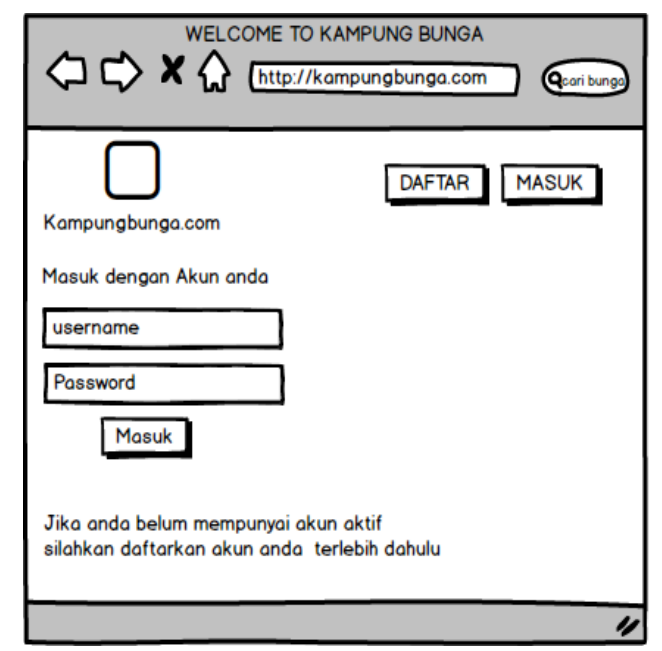

Gambar 2 Rancangan Halaman Registrasi

\section{Tampilan Iklan Bunga}

Tampilan halaman iklan bunga ditampilkan ketika pembeli memilih bunga yang sudah dipilih dan bisa langsung di masukkan kedalam keranjang belanjaan, di halaman ini juga tersedia data-data penjual dan deskirpsi lengkap tanaman bunga yang sudah dipilih seperti harga dan stock tanaman, 


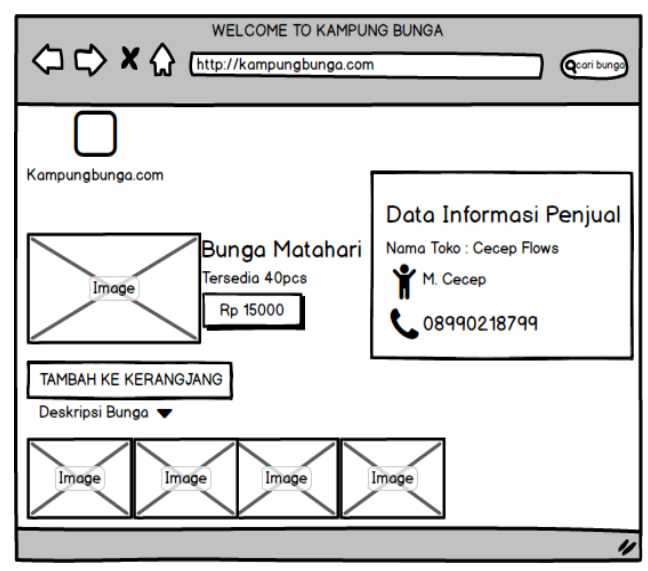

Gambar 3 Rancangan Halaman Iklan Bunga

\section{Hasil dan Pembahasan \\ Hasil Perancangan home}

Halaman home adalah halaman pertama yang muncul saat mengakses kiosalameer.com yang dijalankan pada browserseperti pada Gambar 4 di bawah. Pada halaman ini pengunjung bisa langsung melakukan pemesanan produk, ada juga form login dan registrasi yang harus diisi oleh pengguna yang ingin menjadi pembeli atau penjual, halaman ini juga menampilkan halaman-halaman seperti produk terbaru, kategori, pencarian, dan produk yang ditawarkan, dihalaman ini pengunjung bisa login dan registrasi:

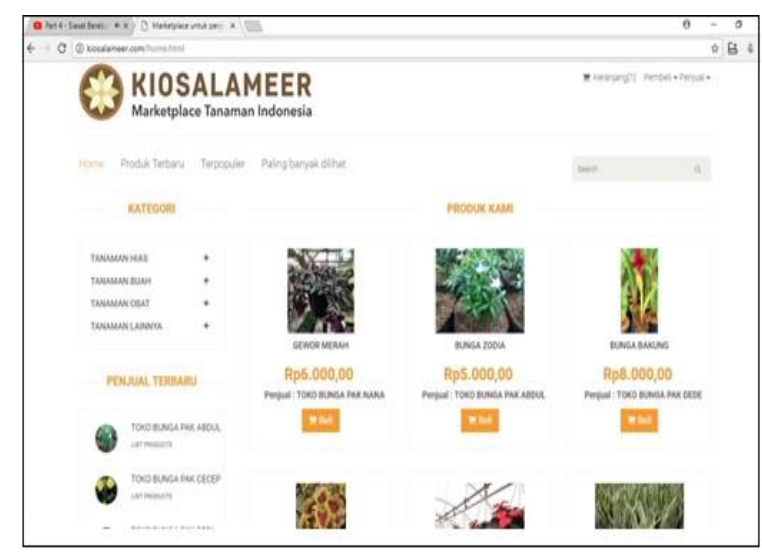

Gambar 4 Halaman Home

\section{Halaman Login}

Pada Gambar di bawah merupakan halaman login pengguna apabila ingin melakukan login. Halaman login digunakan pembeli dan penjual untuk masuk kedalam website jika ingin melakukan pembelian atau penjualan tanaman. Namun sebelumnya pengguna harus melakukan registrasi terlebih dahulu agar bisa masuk ke dalam sistem penjualan ini. 


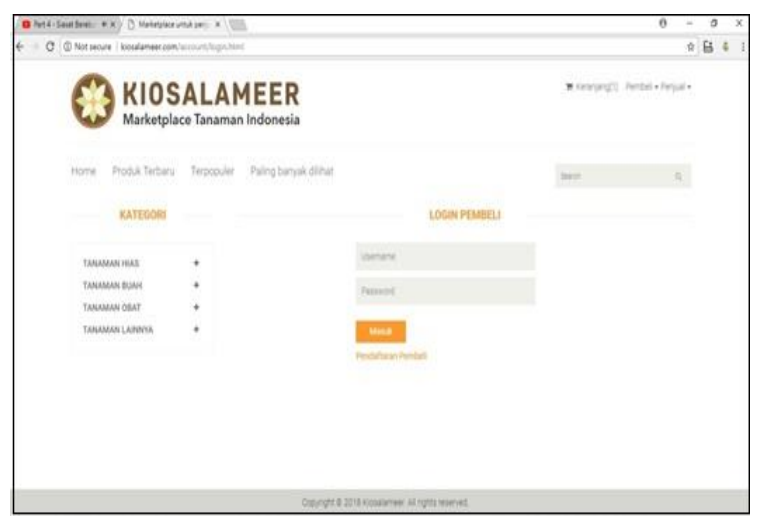

Gambar 5 Halaman Login

\section{Detail Produk}

Pada Gambar 6 di bawah merupakan halaman detail produk penjual apabila ingin membuat detail produk. Halaman detail produk digunakan pembeli untuk melihat deskripsi detail dari tanaman yang ingin dibeli, dari nama tanaman, harga, kategori, sampai deskripsi dan manfaat tanaman tersebut, di halaman ini juga di tampilkan tombol untuk langsung membeli produk tanaman.

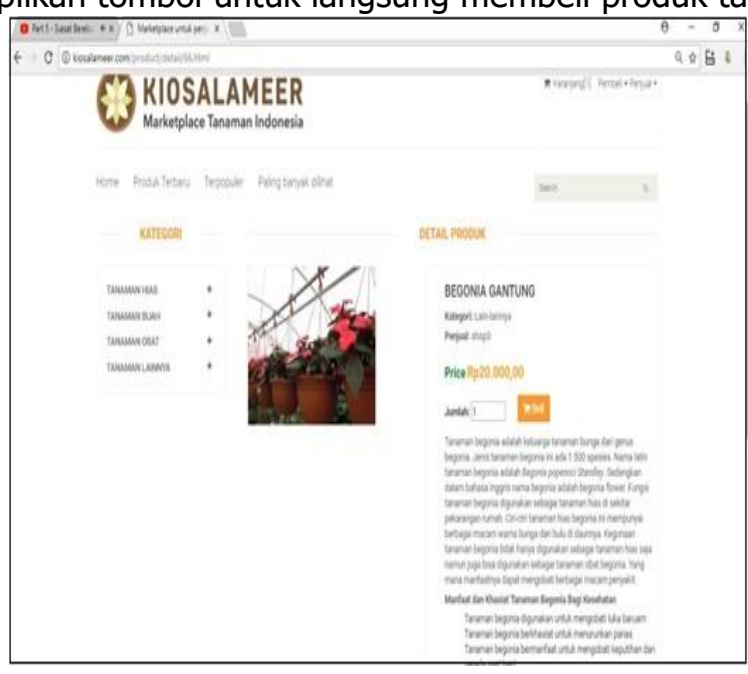

Gambar 6 Halaman Detail Produk

\section{Halaman Home admin}

Pada Gambar di bawah ini merupakan halaman home admin, pada halaman ini juga admin bisa mengatur semua hal yang berhubungan dengan proses transaksi yang terjadi di website kiosalameer.com, di halaman ini admin juga bisa mengecek isi informasi tentang produk, daftar pesanan, daftar penjual dan pembeli 


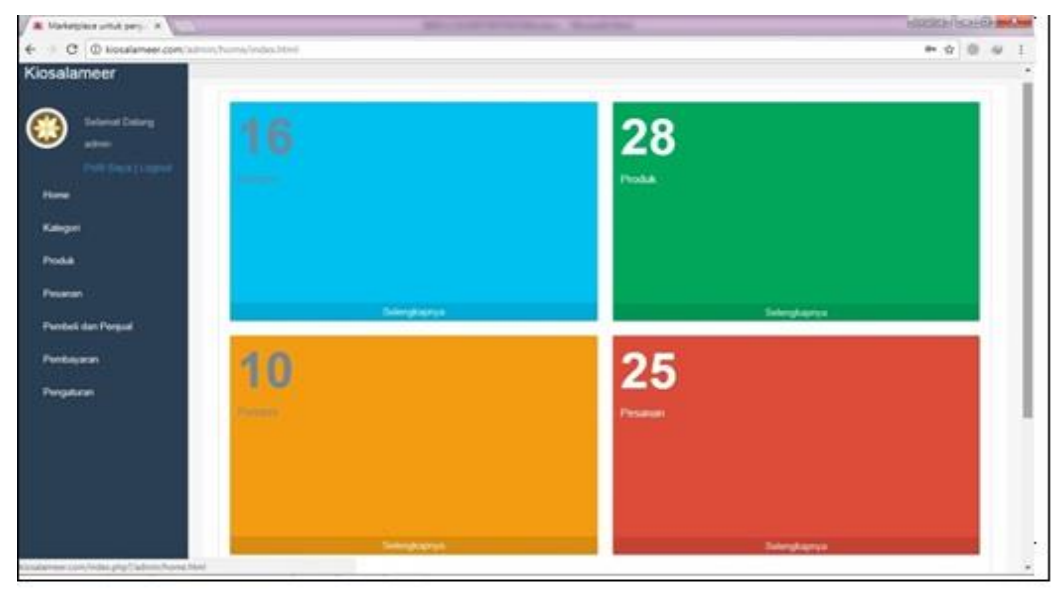

Gambar 7 Halaman Home Admin

\section{Pengujian Sistem}

Pengujian sistem bertujuan untuk mengetahui apakah sistem yang dirancang sudah sesuai dengan yang diharapkan oleh pengguna. Sistem yang telah dirancang akan di uji untuk mengetahui apakah fungsi yang ada sudah sesuai yang diharapkan serta mengetahui kelemahan dari fungsi yang ada. Metode yang akan digunakan oleh penulis adalah metode yang disebut black box testing.

Dengan melakukan metode black box, user atau pengguna akan mengetahui apakah sistem rekrutmen yang dibuat berfungsi sesuai kebutuhan yang diharapkan atau belum. Yang akan diuji dalam black box testing ini adalah spesifikasi perangkat lunak, dimana data akan diuji dan pengguna akan melakukan proses cek hasil keluaran dari sistem apakah sudah sesuai atau belum.

\section{Langkah-langkah Pengujian Sistem}

Langkah-langkah yang akan dilakukan pada proses pengujian, dapat dilihat pada tabel berikut:

Tabel 1 Tahapan Pengujian Sistem

\begin{tabular}{|c|c|c|c|}
\hline No & Fungsi Sistem yang Di Uji & Keterangan & $\begin{array}{l}\text { Jenis } \\
\text { Pengujian }\end{array}$ \\
\hline \multirow{2}{*}{1} & \multirow{2}{*}{ Halaman Registrasi } & Form registrasi & Black Box \\
\hline & & Informasi registrasi & Black Box \\
\hline \multirow{4}{*}{$\begin{array}{l}2 \\
.\end{array}$} & \multirow{4}{*}{ Halaman Pengisian Data Produk } & Tombol Simpan & Black Box \\
\hline & & Tombol Hapus & Black Box \\
\hline & & Upload Foto Produk & Black Box \\
\hline & & Tombol Login & Black Box \\
\hline 3 & Halaman Login & Informasi Kesalahan Login & Black Box \\
\hline 4 & Halaman Data Penjual & Data Tabel penjual & Black Box \\
\hline \multirow{2}{*}{5} & \multirow{2}{*}{ Halaman Data Detail produk } & Tombol produk & Black Box \\
\hline & & Detail Data produk & Black Box \\
\hline 6 & Status Produk & Pilihan Diterima atau Ditolak & Black Box \\
\hline \multirow{2}{*}{7} & \multirow{2}{*}{ Halaman Upload Foto Produk } & Upload foto Produk & Black Box \\
\hline & & Notifikasi berhasil atau gagal & Black Box \\
\hline
\end{tabular}




\begin{tabular}{|l|l|l|l|}
\hline No & Fungsi Sistem yang Di Uji & Keterangan & $\begin{array}{l}\text { Jenis } \\
\text { Pengujian }\end{array}$ \\
\hline \multirow{2}{*}{8} & \multirow{2}{*}{ Halaman Keranjang } & Masuk ke Keranjang & Black Box \\
\cline { 2 - 4 } & & Notifikasi berhasil atau gagal & Black Box \\
\hline 9 & Keluar & Tombol Keluar & Black Box \\
\hline
\end{tabular}

\section{Hasil Pengujian Sistem}

Setelah menentukan tahapan atau langkah-langkah pengujian, berikut adalah hasil dari pengujian Black box testing:

Tabel 2 Hasil Pengujian Sistem

\begin{tabular}{|c|c|c|c|c|}
\hline NO & $\begin{array}{l}\text { Komponen Sistem } \\
\text { yang di uji }\end{array}$ & $\begin{array}{l}\text { Skenario } \\
\text { pengujian }\end{array}$ & $\begin{array}{l}\text { Hasil yang di } \\
\text { Harapkan }\end{array}$ & $\begin{array}{l}\text { Hasil } \\
\text { Pengujian }\end{array}$ \\
\hline 1 & Halaman Registrasi & $\begin{array}{l}\text { Mengklik tombol } \\
\text { Registrasi }\end{array}$ & $\begin{array}{l}\text { Saat pengguna } \\
\text { mengklik persetujuan } \\
\text { baru bisa lanjut }\end{array}$ & Diterima \\
\hline \multirow{2}{*}{2} & \multirow{2}{*}{$\begin{array}{l}\text { Halaman Pengisian } \\
\text { Data Produk }\end{array}$} & $\begin{array}{l}\text { Memasukkan } \\
\text { semua data } \\
\text { informasi yang } \\
\text { sesuai dengan } \\
\text { kebutuhan sistem }\end{array}$ & $\begin{array}{l}\text { Saat pengguna } \\
\text { memasukkan semua } \\
\text { data dengan benar, } \\
\text { maka akan masuk } \\
\text { disimpan ke basis } \\
\text { data }\end{array}$ & Diterima \\
\hline & & $\begin{array}{l}\text { Memasukkan } \\
\text { semua data } \\
\text { informasi yang } \\
\text { tidak sesuai dengan } \\
\text { perintah }\end{array}$ & $\begin{array}{l}\text { Saat pengguna } \\
\text { memasukkan } \\
\text { sebagian data, maka } \\
\text { akan diberitahukan } \\
\text { kesalahan pada } \\
\text { sistem }\end{array}$ & Diterima \\
\hline \multirow[t]{2}{*}{3} & \multirow{2}{*}{ Halaman Login } & $\begin{array}{l}\text { Memasukkan data } \\
\text { username dan } \\
\text { password dengan } \\
\text { benar }\end{array}$ & $\begin{array}{lr}\text { Saat pengguna } \\
\text { memasukkan data } \\
\text { dengan benar, maka } \\
\text { akan masuk ke } \\
\text { halaman home }\end{array}$ & Diterima \\
\hline & & $\begin{array}{lr}\text { Memasukkan } & \text { data } \\
\text { username } & \text { dan } \\
\text { password } & \text { yang } \\
\text { salah } & \end{array}$ & $\begin{array}{l}\text { Saat pengguna } \\
\text { memasukkan data, } \\
\text { maka akan } \\
\text { diberitahukan } \\
\text { kesalahan sistem }\end{array}$ & Diterima \\
\hline 4 & $\begin{array}{l}\text { Halaman } \\
\text { Penjual }\end{array}$ & $\begin{array}{l}\text { Admin meng-klik } \\
\text { menu penjual }\end{array}$ & $\begin{array}{lr}\text { Saat admin membuka } \\
\text { halaman } & \text { data } \\
\text { pembeli, maka akan } \\
\text { menampilkan data } \\
\text { pembeli }\end{array}$ & Diterima \\
\hline 5 & $\begin{array}{l}\text { Halaman Data Detail } \\
\text { produk }\end{array}$ & $\begin{array}{l}\text { Penjual meng-klik } \\
\text { tombol detail yang } \\
\text { ada pada tabel } \\
\text { produk }\end{array}$ & $\begin{array}{l}\text { Saat penjual mengklik } \\
\text { tombol detail maka } \\
\text { akan langsung } \\
\text { dialihkan ke detail } \\
\text { produk }\end{array}$ & Diterima \\
\hline
\end{tabular}




\begin{tabular}{|c|c|c|c|c|}
\hline NO & $\begin{array}{l}\text { Komponen Sistem } \\
\text { yang di uji }\end{array}$ & $\begin{array}{l}\text { Skenario } \\
\text { pengujian }\end{array}$ & $\begin{array}{l}\begin{array}{l}\text { Hasil yang di } \\
\text { Harapkan }\end{array} \\
\end{array}$ & $\begin{array}{l}\text { Hasil } \\
\text { Pengujian }\end{array}$ \\
\hline 6 & Status produk & $\begin{array}{lr}\text { Admin } & \text { akan } \\
\text { memilih apakah } & \text { produk akan } \\
\text { diaktifkan atau di } \\
\text { non-aktifkan untuk } \\
\text { ditampilkan }\end{array}$ & $\begin{array}{lr}\text { Saat admin melihat } \\
\text { detail produk, maka } \\
\text { admin } & \text { akan } \\
\text { disediakan option } \\
\text { untuk status produk, } \\
\text { jika sudah ditetapkan, } \\
\text { makaran } \\
\begin{array}{lr}\text { dikategorikan } & \text { sesuai } \\
\text { produk }\end{array}\end{array}$ & Diterima \\
\hline 7 & $\begin{array}{l}\text { Halaman Upload } \\
\text { Foto Detail Produk }\end{array}$ & $\begin{array}{l}\text { Setelah memilih } \\
\text { foto, maka penjual } \\
\text { akan mengklik } \\
\text { tombol upload } \\
\text { maka sistem akan } \\
\text { mengganti foto dan } \\
\text { menampilkan } \\
\text { notifikasi }\end{array}$ & $\begin{array}{l}\text { Setelah berhasil } \\
\text { upload foto, maka } \\
\text { akan ada notifikasi } \\
\text { berhasil dan jika } \\
\text { gagal maka akan ada } \\
\text { notifikasi gagal }\end{array}$ & Diterima \\
\hline 8 & Halaman Keranjang & $\begin{array}{l}\text { Pengguna } \\
\text { memasukan barang } \\
\text { ke keranjang }\end{array}$ & $\begin{array}{l}\text { Saat pengguna } \\
\text { menekan tombol } \\
\text { check out maka akan } \\
\text { tampil informasi detail } \\
\text { pengiriman }\end{array}$ & Diterima \\
\hline 9 & Keluar & $\begin{array}{l}\text { Pengguna / admin } \\
\text { menekan tombol } \\
\text { Keluar pada menu }\end{array}$ & $\begin{array}{l}\text { Saat pengguna } \\
\text { menekan tombol, } \\
\text { maka halaman akan } \\
\text { langsung dialihkan ke } \\
\text { halaman login } \\
\text { kembali }\end{array}$ & Diterima \\
\hline
\end{tabular}

\section{Analisa Hasil Pengujian}

Berdasarkan pengujian sistem menggunakan metode Black Box, maka penulis dapat menyimpulkan bahwa sistem sudah berjalan dengan baik sesuai dengan fungsi yang diharapkan dan mengeluarkan informasi yang sesuai dengan data yang ada atau produk yang tersimpan didalam basis data yang siap untuk dijual.

\section{Kesimpulan dan Saran \\ Kesimpulan}

Berdasarkan penelitian yang telah dilakukan terhadap sistem, maka kesimpulan yang didapat dari perancangan sistem ini adalah sebagai berikut:

1. Sistem penjualan marketplace ini membantu para petani tanaman bunga desa Cihideung dalam menjual tanaman bunga kepada konsumen yang membutuhkan.

2. Petani dan pembeli bisa dengan mudah mendaftar sebagai penjual atau pembeli dengan bantuan sistem ini karena sistem ini berbasis website online yang dapat diakses kapan saja, di mana saja selagi ada jaringan internet.

3. Sistem penjualan online berbasis web ini memberikan kemudahan kepada customer untuk berbelanja tanpa harus datang ke tempat penjual. 


\section{Saran}

Untuk meningkatkan kualitas sistem penjualan ke depannya disarankan agar fungsi dari sistem pembayaran elektronik yang digunakan bisa dikembangkan dengan membuat sistem pembayaran elektronik secara global seperti kartu kredit agar bisa melayani pembelian pengunjung yang berada di luar negeri.

\section{Referensi}

1. Kadir, A., (2008), Dasar Pemrograman Web Dinamis Menggunakan PHP, Andi: Yogyakarta.

2. Ladjamudin, A., (2005), Analisa dan Desain Sistem Informasi, Graha Ilmu: Yogyakarta.

3. Nugroho, B., (2007), PHP Profesional: Pengembangan Data Array dalam membuat Aplikasi Web, Andi: Yogyakarta.

4. Nugroho, B., (2006), Trik dan Rahasia Membuat Aplikasi Web dengan PHP, Gaya Media: Yogyakarta.

5. Peranginangin, K., (2006), Aplikasi web dengan PHP dan MySQL, Andi: Yogyakarta.

6. Raharjo, B., Heryanto, I., dan Enjang, R.K., (2010), Modul Pemrograman WEB (HTML, PHP dan MYSQL), Modula: Bandung.

7. Sarwono, J., (2006), Strategi Penelitian di Internet, Graha Ilmu: Yogyakarta.

8. Sidik, B., (2007), Pemrograman Web dengan HTML, Informatika: Bandung.

9. Soeherman, B., dan Pinontoan, M., (2008), Designing Information System, Elex Media Komputindo: Jakarta.

10. Sukarno, M., (2006), Membangun Website Dinamis Interaktif dengan PHP - MySQL, Eska Media.

11. Taryana S., dan Sarwono J., (2007), E-Commerce Menggunakan PHP dan MySQL. Graha Ilmu: Yogyakarta. 